\title{
ANALISIS IMPLEMENTASI PROGRAM CORPORATE SOCIAL RESPONSIB ILITY (CSR) TERHADAP LINGKUNGAN DAN KESEJAHTERAAN MASYARAKAT PETANI (STUDI KASUS PADA PT. LSI DI KABUPATEN KUTAI BARAT)
}

\author{
(Implementation Analysis Of Corporate Social Responsibility (CSR) Program For The \\ Environment And Welfare Of Farmer Community (Case Study at PT. LSI In Kutai Barat \\ Regency))
}

\author{
Arista Damayanti, Ida Bagus Made Agung Dwijatenaya, Hyohana Hekiya \\ Program Studi Agribisnis Fakultas Pertanian Universitas Kutai Kartanegara \\ Jl. Gunung Kombeng No 27 Tenggarong Kabupaten Kutai Kartanegara \\ Penulis koresponden: aristadamayanti@unikarta.ac.id
}

Article Submitted : 17-09-2021

Article Accepted :02-01-2022

\begin{abstract}
This study aims to determine the effect of CSR on the environment and on the welfare of the farming community and the influence of the environment on the welfare of the farming community by PT. LSI. This research was conducted in Perigiq Village, Jempang District, Mancong Jempang District, Muara Nayan Jempang District and Gunung Bayan District Muara Pahu Kutai Barat Regency. The research design uses a quantitative research approach, and with data collection techniques through interviews, observations, and documentation. The population in this study was 223 based on the number of farmers, using Simple Random Sampling with a sample of 69 respondents, the analytical test used was SmartPLS v.3.0 with SEM (Structural Equation Modeling) analysis method.The results of the study show that the influence of CSR on the environment has a positive and significant effect, this result is based on the calculation of Path Coefficients obtaining a value of $0,347>0$ which is declared positive and the T-Statistic calculation obtains a value of 2,952>1,96 which states significant. The influence of CSR on Welfare has a positive and significant effect, this result is based on the calculation of Path Coefficients obtaining a value of $0,339>0$ which is declared positive and the T-Statistic calculation obtains a value of 2,607 > 1,96 which states significant. The influence of the environment on welfare has a positive but not significant effect, the environment has a positive but not significant effect on well-being, this result is based on the calculation of Path Coefficients obtaining a value of $0,229>0$ which is declared positive and the T-Statistic calculation obtains a value of $1,785<1,96$ which states that it is not significan, this is because the company has nit yet cared for social responsibility.
\end{abstract}

Keywords: CSR, Environment, Welfare

\section{PENDAHULUAN}

Tanaman perkebunan yang paling luas di Kalimantan Timur adalah Kelapa Sawit dengan luas sebesar 1.228.138 Ha dan total produksi mencapai 18.343.852 Ton pada tahun 2019. Salah satu penghasil kelapa sawit di Kalimantan Timur adalah Kabupaten Kutai Barat memiliki luas tanaman perkebunan Kelapa Sawit adalah 145.125 Ha dan produksi mencapai 1.121.090 Ton (BPS Kaltim, 2020). PT. LSI adalah salah satu perusahaan agribisnis yang bergerak dalam 
bidang perkebunan Kelapa Sawit dengan produk utamanya ialah Crude Palm Oil (CPO).Perusahaan ini memiliki \pm 37 perusahaan inti dan \pm 14 perusahaan plasma yang terletak di Pulau Sumatera, Sulawesi, Kalimantan dan Jawa. Salah satu PT. LSI yang ada di Kalimantan Timur berada di Kecamatan Jempang Kabupaten Kutai Barat telah ada sejak tahun 1996 dan terus melakukan perluasan lahan.

Perusahan perlu melakukan persetujuan Analisis Mengenai Dampak Lingkungan Hidup (AMDAL) mengenai dampak besar yang kemungkinan akan terjadi dilingkungan masyarakat sekitar perusahaan. Adanya aktivitas industri dapat menyebabkan kerusakan lingkungan akibat pencemaran polusi udara, penurunan kualitas air, degradasi tanah, dan rusaknya ekosistem (Ikhsan Dan Muharam, 2016). Permasalahaan sosial, perluasan lahan yang dilakukan PT. LSI mengakibatkan adanya peralihan tanah adat sehingga terjadi konflik antara perusahaan dan masyarakat setempat. Permasalahan lingkungan, adanya peralihan hutan adat menjadi lahan perkebunan sawit menyebabkan rusaknya habitat, salah satunya habitat Bekantan hewan endemik Kalimantan. Maka perusahaan tidak hanya berfokus pada laba/keuntungan materi saja, namun menjadi fokus utama pula tentang kesejahteraan khususnya terhadap masyarakat yang tinggal dekat dengan perusahaan tersebut sehingga masyarakat bisa dapatkan hak - hak kelayakan hidupnya (Suci dkk, 2019).

Analisis implementasi program

Corporate Social Responsibility (CSR) PT. LSI terhadap lingkungan dan kesejahteraan masyarakat ini sangatlah penting demi kelancaran atau keberlanjutan perusahaan di Kecamatan Jempang dan Kecamatan Muara Pahu Kabupatan Kutai Barat.

\section{METODE PENELITIAN}

\section{Waktu dan Tempat}

Penelitian ini dilakukan pada bulan Desember 2020 sampai dengan Febuari
2021. Lokasi penelitian adalah Kampung Perigiq, Mancong, Maura Nayan di Kecamatan Jempang dan Kampung Gunung Bayan Kecamatan Muara Pahu Kabupaten Kutai.

\section{Identifikasi Dan Indikator Varibel Penelitian}

Variabel yang digunakan pada penelitian ini berdasarkan rumusan masalah dan hipotesis maka variabel yang digunakan ialah variabel laten (laten/construct variable) yaitu variabel yang tidak dapat diukur secara langsung (unobservable). Jenis variabel laten dalam penelitian ini meliputi variabel eksogen, dan variabel endogen (Hamid dan Anwar, 2019).

1) Variabel Eksogen

a. Corporate Social Responsibility (X)

CSR, indikator yang diukur adalah perusahaan melaksanakan bantuan dibidang pendidikan $\left(\mathrm{X}_{11}\right)$, perusahaan melaksanakan bantuan dibidang kesehatan $\left(\mathrm{X}_{12}\right)$, perusahaan memberikan bantuan untuk meningkatkan pendapatan $\left(\mathrm{X}_{13}\right)$, perusahaan melakukan pengendalian polusi udara $\left(\mathrm{X}_{14}\right)$, perusahaan melakukan pengendalian kualitas tanah $\left(\mathrm{X}_{15}\right)$, perusahaan melakukan pengendalian kualitas air $\left(\mathrm{X}_{16}\right)$, dan perusahaan melakukan penjagaan/kelestarian ekosistem $\left(\mathrm{X}_{17}\right)$.

2) Variabel Endogen

a. Lingkungan $\left(\mathrm{Y}_{1}\right)$

Pada variable lingkungan indicator yang diukur adalah perusahaan menciptakan lingkungan yang sehat $\left(\mathrm{Y}_{11}\right)$, perusahaan menciptakan lingkungan yang aman $\left(\mathrm{X}_{12}\right)$, perusahaan melakukan perbaikan lingkungan $\left(\mathrm{Y}_{13}\right)$, ketersediaan lahan pertanian terpenuhi $\left(\mathrm{Y}_{14}\right)$, dan tidak melakukan alih fungsi lahan sawah $\left(\mathrm{Y}_{15}\right)$.

b. Kesejahteraan $\left(\mathrm{Y}_{2}\right)$

Kesejahteraan, indikator yang diukur adalah kesejahteraan terhadap kesehatan masyarakat $\left(\mathrm{Y}_{21}\right)$, kesejahteraan terhadap pendidikan masyarakat $\left(\mathrm{Y}_{22}\right)$, kesejahteraan terhadap pendapatan $\left(\mathrm{Y}_{23}\right)$, 
dan kesejahteraan dengan indikator hubungan sosial masyarakat $\left(\mathrm{Y}_{24}\right)$.

\section{Populasi dan Sampel Penelitian}

Pada penelitian ini yang menjadi populasi adalah masyarakat yang berkerja sebagai petani di Kampung Perigiq Kecamatan Jempang, Kampung Mancong Kecamatan Jempang, Kampung Muara Nayan Kecamatan Jempang, dan Kampung Gunung Bayan Kecamatan Muara Pahu dengan jumlah petani sebanyak 223 orang yang berada di sekitar PT. LSI yang terdampak secara langsung terhadap proses oprasional perusahaan.

Perhitungan menggunakan rumus Slovin menghasilkan jumlah sampel sebanyak 69 Responden dengan menggunakan metode Sampel Acak Sederhana (Simple Random Sampling) merupakan metode untuk memilih $\mathrm{n}$ (ukuran sampel) dari N (ukuran populasi) sedemikian rupa sehingga tiap unit dalam sampel mempunyai peluang yang sama untuk dipilih.

\section{HASIL DAN PEMBAHASAN \\ Profil Perusahaan \\ PT. LSI didirikan pada tahun 1906} ketika Harrisons dan Crosfield Plc. Perusahaan perkebunan yang berbasis di London, Inggris memulai lahan perkebunan pertama di Indonesia pada tahun 1995 yang berlokasi di Kota Medan, Sumatera Utara. Kantor pusat di Aribimo Sentral Lt. 12, Jln. HR. Rasuna Said Blok X-2 Kav. 5 Jakarta 12950 - Indonesia dan kantor cabang operasional berlokasi di Sumatera, Sulawesi, Jawa, dan Kalimantan. Tahun awal berdirinya PT. LASI tanaman utama meliputi Karet, Teh, dan Kakao, namun pada tahun 1980an perusahaan mulai melakukan penanaman Kepala Sawit.Hingga saat ini Kelapa Sawit terus tumbuh dan menjadi komoditas penyumbang keuntungan utama bagi perusahaan (PT. LSI, 2014).

\section{Karakteristik Responden}

Penelitian ini menggunakan jumlah sample adalah 69 responden dengan jumlah
Teknik Pengolahan Dan Analisis Data

Model structural equation modeling (SEM) dengan program smartpls 3.0.merupakan salah satu alat analisis statistika, dan merupakan gabungan anatara regresi dan faktor dengan perhitungan matematika yang sangat kompleks. Adapun tujuan dari model ini adalah untuk menguji hubungan- hubungan antar variable baik antara indicator dan konstruk maupun hubungan antar konstruk.

Menurut Jogiyanto dalam Hamid dan Anwar (2019), terdapat dua tahapan evaluasi model dalam PLS-SEM, adalah model pengukuran (outer model) yang terdiri dari (Convergent Validity dan Composite Reliability) dan Model Struktural (Inner Model) yang terdiri dari (R-Squares, FSquare, Path Coefficients, Predictive Relevance, Goodness Of Fit Model, Uji Hipotesis, Direct Effects, Indirect Effects dan Total Effects).

laki-laki 60,87\% dan perempuan 39,13\%. Tingkat pendidikan dominan adalah pendidikan Sekolah Dasar (SD) sedangkan Usia masyarakat petani yang menjadi responden didominasikan 56,52 \% adalah usia 45 - 54 Tahun, dan 28,99\% adalah 55 Tahun ke atas.

\section{Deskripsi Variabel}

1) Variabel CSR (X), Corporate Social Responsibility adalah tanggung jawab sosial perusahaan terhadap masyarakat yang harus dilakukan atau dilaksanakan.

2) Variabel Lingkungan $\left(Y_{1}\right)$, Dampak lingkungan sering terjadi karena adanya aktivitas operasional dari perusahaan.

3) Variabel Kesejahteraan

Kesejahteraan adalah kondisi yang sesuai dengan standar kelayakan kehidupan dalam hal ini yaitu kehidupan petani dengan penghasilan petani yang meningkat dan mampu memenuhi kebutuhan hidup sehari - hari 


\section{Uji Structural Equation Modeling (SEM) Evaluasi Model Pengukuran (Outer Model)}

Outer model melihat hubungan antara variabel laten dengan variable indikator. Dalam penelitian ini menggunakan model indikator refleksi yaitu arah hubungan atau panah dari variabel letan ke indikator yang diharapkan antar indikator saling berkorelasi, jika beberapa indikator dihilangkan maka tidak merubah makna variabel letan. Outer model dilakukan untuk menunjukkan hasil uji validitas yang digunakan untuk mengetahui kemampuan instrument penelitian sedangkan uji reabilitas digunakan untuk mengukur konsistensi alat ukur dalam mengukur suatu konsep dan untuk mengukur konsistensi responden dalam menjawab item pertanyaan dalam kuesioner penelitian. Kriteria pada nilai Convergent Validity dengan nilai loading factor harus > 0,7 dan Nilai AVE (Average Varians Extracted) harus > 0,5 maka dinyatakan valid.

Berdasarkan hasil Uji SEM Outer model dalam penelitian ini Convergent Validity yaitu nilai loading factor terdapat indikator yang dinyatakan tidak valid dengan nilai < 0,7 begitu pula dengan nilai AVE $<0,5$ dinyatakan tidak reliabel, dalam Structural Equation Modeling (SEM) nilai indikator harus valid, jika terdapat nilai yang tidak valid maka indikator tersebut tidak bisa menjadi alat ukur atau mengukur varibel. Maka dilakukan modifikasi agar mendapatkan nilai yang valid, dapat dilihat pada Tabel 1 berikut ini.

Tabel 1. Nilai Loading factor dan Nilai AVE Setelah Di Modifikasi

\begin{tabular}{ccccc}
\hline Indikator & $\begin{array}{c}\text { CSR } \\
(\mathbf{X})\end{array}$ & $\begin{array}{c}\text { Lingkungan } \\
\left(\mathbf{Y}_{1}\right)\end{array}$ & $\begin{array}{c}\text { Kesejahteraan } \\
\left(\mathbf{Y}_{2}\right)\end{array}$ & Kete rangan \\
\hline $\mathrm{X}_{15}$ & 0,897 & & & Valid \\
$\mathrm{X}_{16}$ & 0,825 & & & Valid \\
$\mathrm{Y}_{11}$ & & 0,780 & & Valid \\
$\mathrm{Y}_{13}$ & & 0,854 & & Valid \\
$\mathrm{Y}_{21}$ & & & 0,780 & Valid \\
$\mathrm{Y}_{22}$ & & & 0,780 & Valid \\
$\mathrm{Y}_{23}$ & & & 0,747 & Valid \\
$\mathrm{Y}_{24}$ & & & 0,708 & Valid \\
Average Varians Extracted & 0,743 & 0,669 & 0,570 & Valid \\
\hline Sumbr: Data Prita
\end{tabular}

Sumber : Data Primer Diolah Peneliti,2021

Berdasarkan dari hasil Tabel 1 yang sudah dimodifikasi dapat disimpulkan bahwa indikator CSR hanya tersisa dua yang dinyatakan Valid yaitu $\left(\mathrm{X}_{15}\right.$ : Perusahaan melakukan pengendalian kualitas tanah; dan $\mathrm{X}_{16}$ : Perusahaan melakukan pengendalian kualitas air). Indikator lingkungan hanya tersisa dua yang dinyatakan Valid yaitu ( $\mathrm{Y}_{11}$ : Perusahaan menciptakan lingkungan yang sehat; dan $\mathrm{Y}_{13}$ : Perusahaan melakukakan perbaikan lingkungan). Indikator
Kesejahteraan semua indikator dinyatakan Valid yaitu $\left(\mathrm{Y}_{21}\right.$ : Kesejahteraan dengan indikator terhadap kesehatan masyarakat; $\mathrm{Y}_{22}$ : Kesejahteraan dengan indikator terhadap pendidikan masyarakat; $\mathrm{Y}_{23}$ : Kesejahteraan terhadap pendapatan masyarakat petani; dan $\mathrm{Y}_{24}$ : Kesejahteraan terhadap hubungan sosial masyarakat petani). Berikut ini adalah hasil dari evaluation of measurement model yang sudah dimodifikasi. 


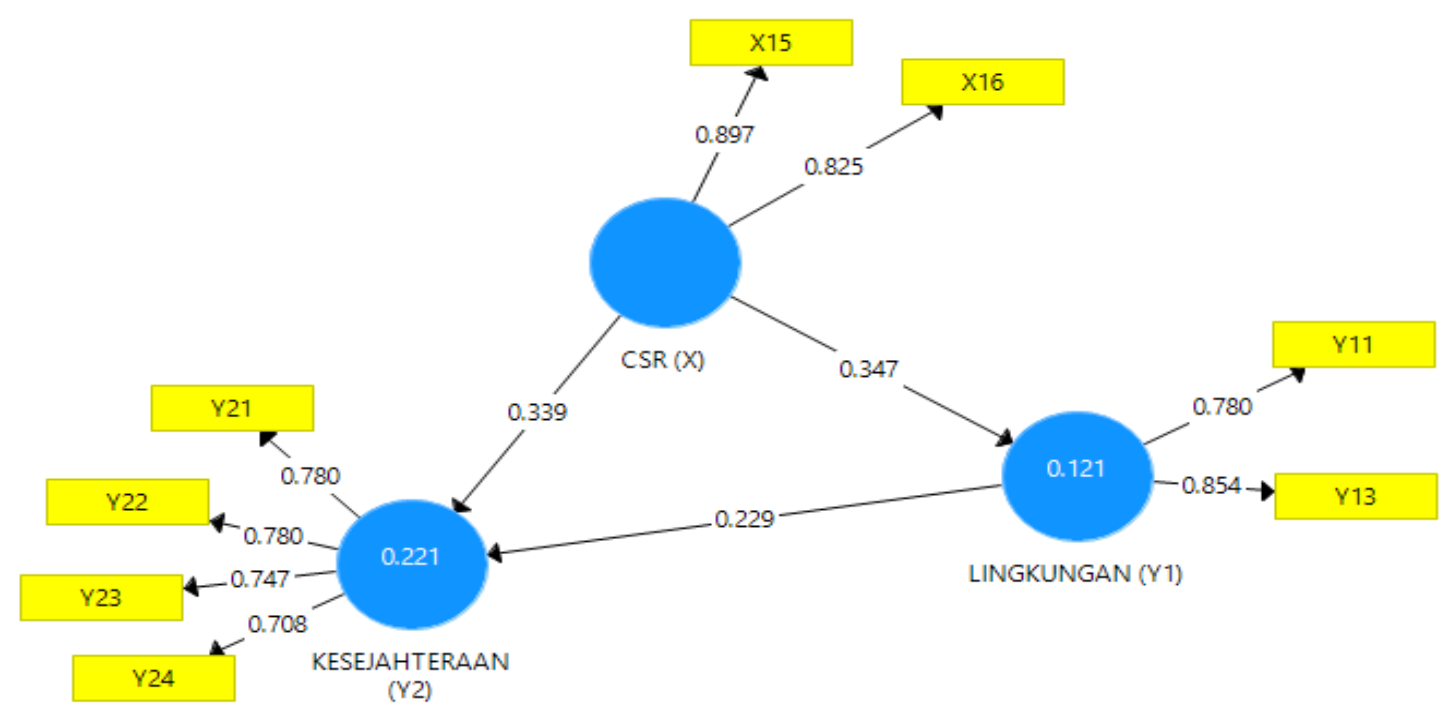

Gambar 1. Hasil Uji Outer Model setelah dimodifikasi, 2021

Uji reabilitas digunakan untuk mengukur konsistensi alat ukur dalam mengukur suatu konsep dan untuk mengukur konsistensi responden dalam menjawab item pertanyaan dalam kuesioner penelitian dapat dilihat pada nilai Composite Reliability > 0,7 dinyatakan reliabel, dapat dilihat pada gambar berikut.

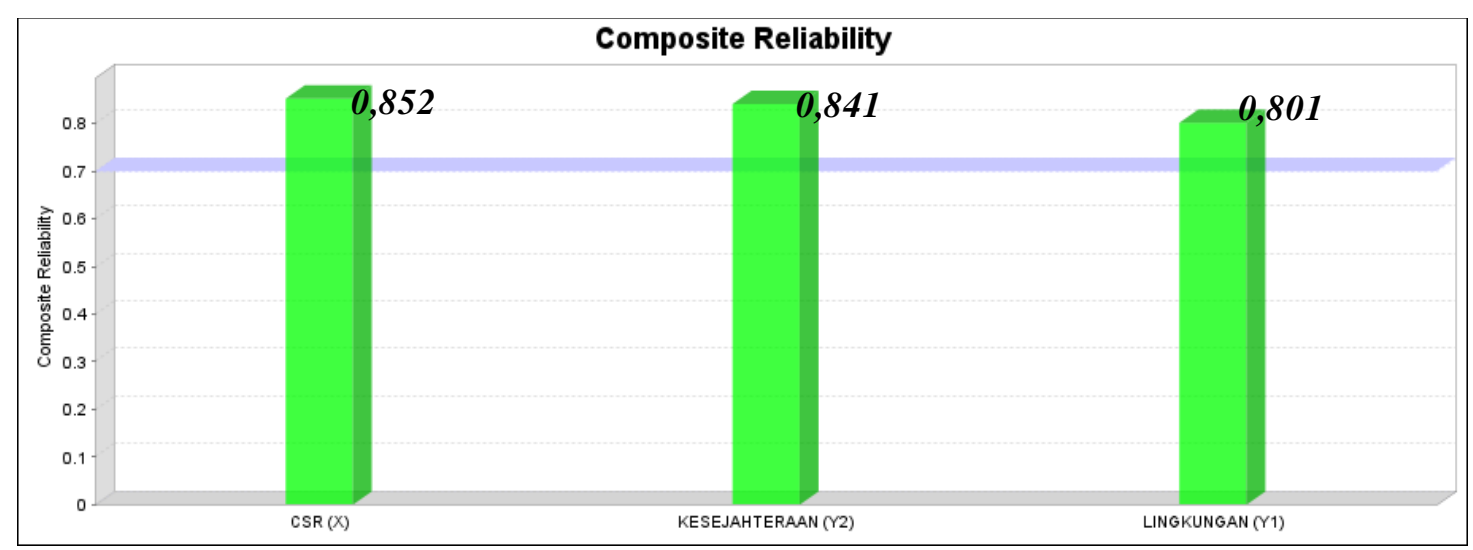

Gambar 2. Hasil nilai Composite Reliability, 2021

Berdasarkan dari Gambar 2. Dapat disimpulkan bahwa semua nilai di atas 0,7 maka variabel yang diuji dinyata Reliabel,

\section{Evaluasi Model Struktural (Inner Model)}

Menurut Jogiyanto dalam Hamid dan Anwar (2019), ada beberapa komponen yang menjadi penilaian inner model adalah nilai $R$ Square, Effect Size f ${ }^{2}, Q$-Square, predictive relevancedan, Goodness Of Fit (GoF), dan Signifikansi. R-Square, menilai besarnya sehingga dapat dilakukan analisis elanjutnya yaitu pengujian model structural.

pengaruh variabel laten endogen tertentu terhadap variabel laten eksogendengan kriteria jika 0,75 (kuat) 0,50 (moderat) dan 0,25 (lemah) (Hair dalam Saputra, 2018). Hasil perhitungan variabel dapat dijelaskan oleh variabel CSR dalam model sebesar 12 
$\%$, termasuk dalam kategori lemah. Variabel kesejahteraan dapat dijelaskan oleh variabel CSR dan lingkungan dalam model sebesar $22 \%$ juga termasuk dalam kategori lemah.
Maka 65,4 \% dipengaruhi oleh variabel lain diluar varibel dalam penelitian ini sebagaimana disajikan pada tabel 2 berikut ini.

Tabel 2. Nilai R-square, 2021

\begin{tabular}{lccc}
\hline & R_Square & R_Square Adjusted & Ke te rangan \\
\hline CSR $(\mathbf{X})$ & & & \\
Lingkungan $\left(\mathbf{Y}_{1}\right)$ & 0,121 & 0,108 & Lemah \\
Kesejahteraan $\left(\mathbf{Y}_{2}\right)$ & 0,221 & 0,198 & Lemah \\
\hline
\end{tabular}

Sumber : Data Primer Diolah Peneliti

F- square, digunakan untuk melihat besar atau kecil pengaruh antar variabel dengan kriteria $0,02 \quad$ (Kecil); 0,15 (menengah); dan 0,35 (besar) yang berarti bahwa prediktor variabel laten memiliki pengaruh pada level structural.
Path Coefficients, nilai untuk menunjukan arah hubungan variabel.Terdapat dua arah yaitu arah positif dan negatif, dikatakan positif jika nilai $>0$ dan dikatakan negative jika nilai $<0$. Berikut ini tabel nilai F- square dan Path Coefficients.

Tabel 3. Nilai F- square dan Path Coefficients, 2021

\begin{tabular}{lcc}
\hline & F- square & Path Coefficients \\
\hline \multirow{2}{*}{ CSR $(\mathrm{X}) \rightarrow$ Lingkungan $\left(\mathrm{Y}_{1}\right)$} & 0,137 & 0,347 \\
& $($ Kecil) & $($ Positif $)$ \\
CSR $(\mathrm{X}) \rightarrow$ Kesejahteraan $\left(\mathrm{Y}_{2}\right)$ & 0,130 & 0,339 \\
& $($ Kecil) & $($ Positif $)$ \\
Lingkungan $\left(\mathrm{Y}_{1}\right) \rightarrow$ Kesejahteraan $\left(\mathrm{Y}_{2}\right)$ & 0,059 & 0,229 \\
& $($ Kecil) & (Positif) \\
\hline
\end{tabular}

Sumber : Data Primer Diolah Peneliti

Berdasarkan hasil dari Tabel 3, dapat dijelaskan sebagai berikut. Pengaruh CSR terhadap Lingkungan; CSR (X) $\rightarrow$ Lingkungan $\left(\mathrm{Y}_{1}\right)$, nilai $\mathrm{F}$ - square adalah 0,137 (Kecil) dan nilai Path Coefficients sebesar 0,347 (Positif) artinya CSR berpengaruh kecil dan positif terhadap Lingkungan.

Pengaruh CSR terhadap Kesejahteraan; CSR (X) $\rightarrow$ Kesejahteraan $\left(\mathrm{Y}_{2}\right)$, nilai $\mathrm{F}$ square adalah 0,130 (Kecil) dan nilai Path Coefficients sebesar 0,339 (Positif) hal ini menyatakan bahwa artinya CSR berpengaruh kecil dan positif terhadap kesejahteraan.
Pengaruh lingkungan terhadap kesejahteraan ; Lingkungan $\left(\mathrm{Y}_{1}\right) \rightarrow$ Kesejahteraan $\left(\mathrm{Y}_{2}\right)$, nilai $\mathrm{F}$ - square adalah 0,059 (Kecil) dan nilai Path Coefficients sebesar 0,229 (Positif) artinya lingkungan berpengaruh kecil dan positif terhadap kesejahteraan.

Predictive Relevance, menunjukkan bahwa model mempunyai predictive relevance atau nilai observasi yang baik, sedangkan nilai $\mathrm{Q}^{2}<0$ menunjukkan bahwa model kurang memiliki predictive relevance atau nilai observasi yang tidak baik, dapat dilihat pada tabel berikut. 
Tabel 4. Predictive Relevance

\begin{tabular}{lccc}
\hline & SSO & SSE & $\mathbf{Q}^{\mathbf{2}}$ (= 1-SSE/SSO) \\
\hline CSR $(\mathbf{X})$ & 138.000 & 138.000 & 0 \\
Lingkungan $\left(\mathbf{Y}_{\mathbf{1}}\right)$ & 138.000 & 129.342 & 0,063 \\
Kesejahteraan $\left(\mathbf{Y}_{2}\right)$ & 276.000 & 245.365 & 0,111 \\
\hline
\end{tabular}

Sumber : Data Primer Diolah Peneliti,2021

Berdasarkan hasil dari Tabel 4. Menunjukan nilai $\mathrm{Q}^{2}$ di atas 0 maka semua variabel model mempunyai predictive relevance atau nilai observasi yang baik.

Goodness Of Fit, Menurut Saputra (2018), untuk memvalidasi model secara keseluruhan digunakan Goodness of fit untuk evaluasi model pengukuran dan model sruktural, pengukuran sederhana untuk prediksi model. Berdasarkan pada kriteria

Tabel 5. Goodness Of Fit Model

\begin{tabular}{lcc}
\hline & Saturated Model & Estimated Modal \\
\hline SRMR & 0,103 & 0,103 \\
d_ULS & 0,381 & 0,381 \\
d_G & 0,158 & 0,158 \\
Chi_Square & 70,415 & 70,415 \\
NFI & 0,446 & 0,446 \\
\hline rms Theta & $\mathbf{0 , 3 3 4}$ & \\
\hline
\end{tabular}

Sumber : Data Primer Diolah Peneliti,2021

Berdasarkan dari hasil Tabel 5 . Memiliki nilai rms Theta adalah 0,334 > 0,102 , nilai SRMR adalah $0,103>0,10$ dan nilai NFI $0,446<0,90$ dapat disimpulkan bahwa model dalam penelitian ini belum memenuhi kriteria fit model yang baik. Namun dari nilai NFI adalah 0,446 jika di persentasekan maka Fit model dalam penelitian ini hanya sebesar 44,6 \% di kategorikan cukup kuat.

Uji Hipotesis, dalam penelitian ini menggunakan taraf signifikansi $5 \%$ atau 0,05 yaitu dengan nilai 1,96 . Jika nilai $T$ Statistic > 1, 96 dinyatakan signifikan dan
SRMR < 0,10; nilai d_ULS dan d_G $<95$ $\%$; Chi-square > 0,05; NFI >0,90 dan RMS Theta < 0,102. Namun nilai NFI dapat dikategorikan dengan kriteria nilai $\mathrm{GoF}$ adalah $\quad 0,10 \quad(G o F \quad$ small), 0,25 (GoF medium) dan 0,36 (GoF large) (Widayat, 2019). Maka hasil perhitungan Goodness $O f$ Fit model pada penelitian ini dapat dilihat pada tabel 5 berikut ini. 
Tabel 6. Uji Hipotesis Hubungan Antar Variabel Penelitian

\begin{tabular}{lcccc}
\hline & $\begin{array}{c}\text { T- } \\
\text { Stastistik }\end{array}$ & $\begin{array}{c}\boldsymbol{P} \text { Values } \\
\text { Value }\end{array}$ & Significant & Keterangan \\
\hline CSR $(\mathrm{X}) \rightarrow$ Lingkungan $\left(\mathrm{Y}_{1}\right)$ & 2,952 & $\mathbf{0 , 0 0 3}$ & Sig. & $\mathrm{H}_{1}$. Diterima \\
CSR $(\mathrm{X}) \rightarrow$ Kesejahteraan $\left(\mathrm{Y}_{2}\right)$ & 2,607 & $\mathbf{0 , 0 0 9}$ & Sig. & $\mathrm{H}_{2}$ Diterima \\
$\begin{array}{l}\text { Lingkungan }\left(\mathrm{Y}_{1}\right) \rightarrow \\
\text { Kesejahteraan }\left(\mathrm{Y}_{2}\right)\end{array}$ & 1,785 & $\mathbf{0 , 0 7 5}$ & Tidak sig. & $\mathrm{H}_{3}$. Ditolak \\
& & & & \\
\hline
\end{tabular}

Sumber : Data Primer Diolah Peneliti, 2021

Pengaruh CSR terhadap Kesejahteraan; CSR (X) $\rightarrow$ Kesejahteraan $\left(\mathrm{Y}_{2}\right)$, memiliki nilai 2,607 > 1,96 hubungan CSR terhadap kesejahteraan berpengaruh signifikan, dan hipotesis kedua yang menyatakan bahwa CSR berpengaruh signifikan terhadap kesejahteraan dapat diterima.

Pengaruh Lingkungan terhadap kesejahteraan; Lingkungan $\left(\mathrm{Y}_{1}\right) \rightarrow$ Kesejahteraan $\left(\mathrm{Y}_{2}\right)$, memiliki nilai 1, $785<$ 1,96 maka hubungan variabel Lingkungan terhadap variabel kesejahteraan berpengaruh tidak signifikan, dan hipotesis ketiga ditolak.

Direct Effects, melihat pengaruh langsung antar hubungan variabel nilai path coefficient bootstrapping $>0$ (positif), nilai $<0$ (negatif) dan dilihat juga nilai $P$-Values $<0,05$ (Signifikan), jika nilai $P$-Values > 0,05 (tidak Signifikan).

Indirect Effects, melihat pengaruh tidak langsung antara variabel eksogen terhadap variabel endogen yang diantarai/dimediasi oleh variabel mediator, jika nilai nilai $P$ Values $<0,05$ (Signifikan) artinya variabel mediator memediasi pengaruh variabel eksogen terhadap variabel endogen dan dinyatakan pengaruhnya tidak langsung. Nilai $P$-Values $>0,05$ (tidak Signifikan) artinya variabel mediator tidak memediasi pengaruh variabel eksogen terhadap variabel endogen dan dinyatakan pengaruhnya adalah langsung.
Total Effects, merupakan pengaruh total dari Direct Effectsdan antar variabel. Berikut Direct Effects, Indirect Effectsdan Total Effects dapat dilihat pada Tabel 7.

Pengaruh langsung CSR terhadap Lingkungan dengan nilai $0,347>0$ dan $P$ Values $0,002<0,05$ artinya pengaruh langsung CSR terhadap lingkungan adalah positif dan signifikan. Pengaruh total CSR terhadap lingkungan adalah 0,347.

Pengaruh langsung CSR terhadap Kesejahteraan dengan nilai 0,339>0 dan $P$ - Values $0,008<0,05$ artinya pengaruh langsung CSR terhadap kesejahteraan adalah positif dan signifikan. Pengaruh tidak langsung $(\mathrm{X}) \rightarrow\left(\mathrm{Y}_{1}\right) \rightarrow\left(\mathrm{Y}_{2}\right)$ dengan nilai $P$ Values $0,189>0,05$ dinyatakan tidak signifikan, artinya variabel mediator yaitu lingkungan $\left(\mathrm{Y}_{1}\right)$ tidak memediasi pengaruh variabel CSR (X) terhadap variabel Kesejahteraan $\left(\mathrm{Y}_{2}\right)$ dan dinyatakan pengaruhnya adalah langsung. Pengaruh total CSR terhadap kesejahteraan adalah $41,9 \%$.

Pengaruh langsung Lingkungan terhadap Kesejahteraan dengan nilai 0,229 $>0$ dan $P$ - Values $0,066>0,05$ artinya pengaruh langsung lingkungan terhadap kesejahteraan adalah positif namun tidak signifikan. Pengaruh total lingkungan terhadap kesejahteraan adalah 0,229. 
Tabel 7. Koefisien Jalur dan P-Value BootstrappingDirect Effects, Indirect Effects dan Total Effects

\begin{tabular}{|c|c|c|c|c|c|}
\hline & \multicolumn{3}{|c|}{ Koefisien Jalur } \\
\hline & & & Langsung & Tidak langsung & Total \\
\hline \multirow[t]{2}{*}{$\operatorname{CSR}(\mathrm{X})$} & $\rightarrow$ & Lingkungan $\left(\mathrm{Y}_{1}\right)$ & 0,347 & 0,000 & 0,347 \\
\hline & $\rightarrow$ & Kesejahteraan $\left(\mathrm{Y}_{2}\right)$ & 0,339 & 0,079 & 0,149 \\
\hline \multirow[t]{3}{*}{ Lingkungan $\left(\mathrm{Y}_{1}\right)$} & $\rightarrow$ & Kesejahteraan $\left(\mathrm{Y}_{2}\right)$ & 0,229 & 0,000 & 0,229 \\
\hline & & & & P-Value & \\
\hline & & & Langsung & Tidak langsung & Total \\
\hline \multirow[t]{2}{*}{$\operatorname{CSR}(\mathrm{X})$} & $\rightarrow$ & Lingkungan $\left(\mathrm{Y}_{1}\right)$ & 0,002 & 0,000 & 0,002 \\
\hline & $\rightarrow$ & Kesejahteraan $\left(\mathrm{Y}_{2}\right)$ & 0,008 & 0,189 & 0,197 \\
\hline Lingkungan $\left(\mathrm{Y}_{1}\right)$ & $\rightarrow$ & Kesejahteraan $\left(\mathrm{Y}_{2}\right)$ & 0,066 & 0,000 & 0,066 \\
\hline
\end{tabular}

Sumber : Data Primer Diolah Peneliti,2021

\section{Pengaruh CSR Terhadap Lingkungan}

Aktivitas industri perusahaan dapat menyebabkan kerusakan lingkungan akibat pencemaran polusi udara, penurunan kualitas air, terjadi degradasi tanah, dan mengakibatkan rusaknya ekosistem. Hasil penelitian ini menunjukan bahwa CSR berpengaruh signifikan terhadap lingkungan, berdasarkan dari nilai T-Stastistics 2,952 > 1,96 dan berpengaruh positif dilihat dari nilai Path Coefficients 0,347>0. Namun berpengaruh lemah ditunjukkan dari nilai R-Square 0,121 yang dinyatakan lemah. Berdasarkan jawaban yang diberikan responden merasa tidak setuju terhadap semua indikator tepatnya pada indikator yang nyatakan valid. Indikator CSR $\left(\mathrm{X}_{15}\right.$, $\left.\mathrm{X}_{16}\right)$ dan indikator lingkungan $\left(\mathrm{Y}_{11}, \mathrm{Y}_{13}\right)$ hal ini ditujukan dari nilai skor yang muncul adalah skor 1 dan 2 yang dikategorikan tidak baik.

CSR terhadap aspek kualitas tanah : kualitas tanah adalah mutu tanah yang dapat berfungsi secara alami terhadap ekosistem yang dikelola untuk memelihara produktivitas tanaman dan hewan, dan meningkatkan kesehatan manusia (Larson dan Pierce dalam Suleman dkk, 2016). Namun jawaban responden menyatakan bahwa perusahaan belum melakukan pengendalian kualitas tanah, mengingat bahwa PT. LSI memiliki Pabrik Kelapa
Sawit, sehingga akan menimbulkan penurunan kualitas tanah sejalan dengan pendapat Yakin (2014), yang menyatakan bahwa lahan kelapa sawit memiliki pengaruh yang lebih besar terhadap penurunan kualitas tanah dibandingkan dengan tanaman karet. Hal ini pun dirasakan petani berkurangnya kesuburan tahan maupun tanaman di lahan pertaniannya, tanah yang kering, keras dan pecah - pecah dan lain - lain.

CSR terhadap aspek kualitas air: Perusahaan melakukan pengendalian kualitas air. Menurut Keputusan Menteri Negara Lingkungan Hidup Pasal 1 huruf $b$ No. 115 Tahun 2003 tantang pendoman penentuan status mutu air berbunyi; " Status mutu air adalah tingkat kondisi mutu air yang menujukkan kondisi cemar atau kondisi baik pada suatu sumber air dalam waktu tertentu dengan membandingkan dengan baku mutu air yang ditetapkan" (Kepmen LH, 2003). Berdasarkan jawaban responden perusahaan belum melakukan pengendalian kualitas air. Menurut Apriyanto (2008), limbah cair pabrik kelapa sawit (PKS) akan mencemari badan air penerima curahan limbah tersebut sehingga berdampak pada penurunan kualitas air dan pada saat hari hujan limbah akan meluap masuk ke sungai. Kebutuhan air kelapa sawit sangat banyak yaitu sebesar 4,10 4,65 mm/hari (Hidayat dkk, 2013). Dampak 
tersebut pun dirasakan petani adanya kekurangan ketersediaan air terhadap lahan pertanian dan air segera habis jika $2-3$ hari tidak turun hujan. Dampak juga dirasakan masyarakat, mengingat bahwa ketersediaan air didapat dari sungai yang menunjang kebutuhan hidup sehari - hari seperti (mandi, mencuci, dan lain - lain), jalur transportasi, dan sumber perikanan. Masyarakat menyadari adanya pencemaran kualitas air seperti berkurangnya jumlah ikan atau keresediaan ikan, air yang berbau, air yang berminyak dan lain - lain.

CSR terhadap aspek kesehatan : Perusahaan menciptakan lingkungan yang sehat. Menurut Rahayu (2016), lingkungan sehat adalah kesehatan mental, fisik, dan sosial, suatu keseimbangan dalam ekologi sehingga dapat tercapainya kualitas hidup yang baik bagi manusia. Berdasarkan jawaban responden, perusahaan belum menciptakan lingkungan yang sehat, hal tersebut dapat dirasakan adanya polusi udara akibat dari asap pabrik, pencemaran air akibat limbah PKS, akses jalan umum sebagaian rusak akibat kendaraan berat salah satu truk perusahaan pengangkut sawit tidak jarang hal ini menimbulkan kecelakaan, dan lain - lain.

CSR terhadap aspek perbaikan lingkungan: Perusahaan melakukan perbaikan lingkungan. Jawaban responden menyatakan bahwa perusahaan belum melakukan perbaikan lingkungan, hal ini dirasakan petani dan juga masyarakat, masih banyak dampak negatif yang ditimbulkan perusahaan seperti pencemaran lingkungan akibat asap pabrik, limbah pabrik, dan dan lain - lain. Berdasarkan hasil perhitungan menunjukan hasil pengaruh langsung (Direct Effects) dan pengaruh total (Total Effects) CSR terhadap lingkungan memiliki nilai yang sama adalah 0,347 jika dipersentasekan sebesar 34,7\%.

Pengaruh CSR terhadap lingkungan adalah berpengaruh positif dan signifikan. Temuan ini sejalan dengan hasil penelitian
Harto (2016) dan Nejati dan Ghasemi (2013).

\section{Pengaruh CSR Terhadap Kese jahteraan}

Kesejahteraan membantu masyarakat agar dapat tumbuh dan berkembang dengan berbagai dukungan kondisi yang sesuai standar kelayakan kehidupan individu dan masyarakat selain itu kelayakan hidup secara sosial (Haryono dkk, 2018). Program CSR harus mengarah pada kesehatan, pendidikan, ekonomi dan infrastruktur yang dirancang untuk meningkatkan mutu pembangunan masyarakat. Hasil penelitian ini menunjukan bahwa CSR berpengaruh signifikan terhadap Kesejahteraan, dari nilai T-Stastistics 2,607 $>$ 1,96 dan berpengaruh positif dilihat dari nilai Path Coefficients $0,339>0$. Nilai RSquare 0,221 maka dinyatakan lemah. Responden menyatakan tidak setuju terhadap semua indikator kesejahteraan yang nyatakan valid adalah $\left(\mathrm{Y}_{21}, \mathrm{Y}_{22}, \mathrm{Y}_{23}\right.$, dan $\left.\mathrm{Y}_{24}\right)$.

CSR terhadap aspek kesehatan : Menurut WHO dalam Eliana dan Sumiati (2016), kesehatan masyarakat adalah keadaan yang mempengaruhi kesehatan yang mencangkup penyakit, kualitas makanan, penyediaan jasa kesehatan, dan keamanan pada masyarakat. Berdasarkan jawaban responden bawah perusahaan belum melakukan peningkatan terhadap kesehatan masyarakat, perusahaan telah mendirikan klinik kesehatan namun hanya dipergunakan untuk perusahaan tidak untuk masyarakat.

CSR terhadap aspek pendidikan : Perusahaan belum pernah memberikan bantuaan beasiswa kepada masyarakat yang berkemampuan secara akademis namun tidak mampu membiayai pendidikannya, pelatihaan keterampilan, seminar edukasi, dan lain - lain. Perusahaan hanya mediakan fasilitas transportasi untuk anak sekolah bagi orang tua yang menjadi karyawan perusahaan.

CSR terhadap aspek pendapatan : Berdasarkan jawaban responden, perusahaan belum melakukan, dinyatakan dengan tegas 
oleh responden, karena perusahaan belum pernah memberikan bantuan salah satunya seperti modal UMKM, peningkatan pendapatan masyarakat. bekerjasama dengan Koperasi, dan BUMDes atau BUMKam, dan lain - lain.

CSR terhadap aspek hubungan sosial : Responden menyatakan perusahaan belum dapat menjalin hubungan sosial dengan petani dan masyarakat. Dirasakan perani dan masyarakat saat perusahaan melakukan perluasan lahan, dari tanah adat sebagai sumber penghasilan menjadi lahan

\section{Pengaruh Lingkungan Terhadap Kesejahteraan}

Lingkungan berpengaruh tidak signifikan terhadap Kesejahteraan. Ditunjukkan dari nilai T-Stastistics 1,785 < 1,96 namun berpengaruh positif dilihat dari nilai Path Coefficients 0,229 >0. Nilai Fsquare memiliki nilai 0,059 yang berarti lingkungan berpengaruh kecil terhadap kesejahteraan. Dari hasil pengujian hipotesis bahwa $\mathrm{H}_{3}$ ditolak, hal ini terjadi karena masyarakat belum mempertimbangkan kondisi lingkungan, dimana banyak masyarakat yang melakukan pembukaan lahan dengan cara dibakar, membuang sampah sembarang seperti membuang ke sungai ditambah perusahaan yang belum melaksanakan tanggung jawab sosial dan lingkungan sehingga berdampak buruk, terhadap lingkungan dan berpengaruh terhadap kesejahteraan masyrakat itu sendiri.

Perusahan perlu melakukan analisis AMDAL mengenai dampak besar yang kemungkinan akan terjadi dilingkungan masyarakat sekitar perusahaan dan harus meningkatkan kualitas lingkungan dengan memperhatikan kesehatan lingkungan masyarakat yang melibatkan petani dalam memperbaiki lingkungan sehingga dapat mendorong peningkatan pendapatan dan kesejahteraan petani.

Pengaruh lingkungan tidak signifikan terhadap kesejahteraan.Temuan ini sejalan dengan penelitian Mahfuzah dan Maimunah (2019). Namun Sependapat dengan Bella perkebunan kelapa sawit milik perusahaan sehingga menimbulkan konflik antara petani, dan masyarakat kepada pihak perusahaan. Menyebabkan hilangnya mata pencaharian masyarakat, rusaknya habitat hewan maupun tumbuhan, salah satunya habitat bekantan.

Pengaruh CSR terhadap Kesejahteraan adalah berpengaruh positif dan signifikan.Temuan ini sejalan dengan hasil penelitian Haryonto dkk (2018), Mapisangka (2009), Saputra dkk (2017), Siregar (2019), Naser dan Bandrang (2020).

dkk (2015), yang menyatakan kondisi fisik lingkungan akan diikuti dengan kesejahteraan jika kondisi fisik lingkungan ditingkatkan maka kesejahteraan akan meningkat pula.

\section{KESIMPULAN}

CSR berpengaruh positif dan signifikan terhadap Lingkungan. Namun pengaruh CSR terhadap lingkungan hanya berpengaruh kecil, penyataan tersebut berdasarkan dari perhitungan Fsquarememperoleh nilai $0,137<0,15$ (kecil). Kecilnya pengaruh tersebut disebabkan perusahaan belum melakukan program CSR dalam aspek lingkungan.

CSR berpengaruh positif dan signifikan terhadap kesejahteraan. Pengaruh langsung (Direct Effects) CSR terhadap kesejahteraan adalah sebesar 33,9 \%. Pengaruh tidak langsung (Indrect Effects) (X) $\rightarrow\left(\mathrm{Y}_{1}\right) \rightarrow$ $\left(\mathrm{Y}_{2}\right)$ adalah 0,079 dan nilai $P$ - Values 0,189 $>0,05$ (Tidak Signifikan) artinya variabel mediator yaitu lingkungan (Y1) tidak memediasi pengaruh variabel CSR (X) terhadap variabel Kesejahteraan (Y2) dan dinyatakan pengaruhnya adalah langsung, jika lingkungan dikelola melalui program CSR maka akan berpengaruh terhadap kesejahteraan. Nilai pengaruh total (Total Effects) adalah 0,419 dipersentasekan sebesar $41,9 \%$.

Lingkungan berpengaruh positif namun tidak signifikan terhadap Kesejahteraan. Nilai Path Coefficients memperoleh hasil 
sebesar 0,229> 0 yang (positif) dan perhitungan $T$ - Statistic memperoleh hasil sebesar1,785< 1,96 yang (tidak signifikan). Adanya pengaruh kecil tersebut selain perusahaan belum melakukan program CSR, masyarakat belum memperhatikan kondisi lingkungan sehingga berdampak buruk, terhadap lingkungan dan berpengaruh terhadap kesejahteraan masyarakat itu sendiri.

\section{DAFTAR PUSTAKA}

BPS Kalimantan Timur. 2020. Provinsi Kalimantan Timur Dalam Angka 2019. Samarinda: BPS Kalimanta Timur.

Apriyanto, H. 2008. Kajian Status Kualitas Air Kewasan Pabrik Kelapa Sawit (Pks) Di Pulau Bangka Provinsi Kepulauan Bangka Belitung., 2(2), 50-58.

Bella, P.A, Winny Astuti, dan Galing Yudana.2015. Pengaruh Perubahan Fisik Lingkungan Terhadap Perubahan Kesejahteraan Masyarakat Pada Program Relokasi Permukiman Bantaran Sungai Bangawan Solo Kota Surakarta. Fak.Teknik Universitas Sebelas Maret Surakarta.

Eliana dan Sumiati, Sri. 2016. Kesehatan Masyarakat. Cetakan 1.Jakarta : Pusdik SDM Kesehatan.

Hamid, Rahmad Solling dan Suhardi M. Anwar. 2019. Structural Equation Modeling (Sem) Berbasis Varian: Konsep Dasar Dan Aplikasi Dengan Program Smartpls 3.2.8 Dalam Riset Bisnis. Cetakan 1. Jakarta: PT Inkubator Penulis Indonesia.

Harto, P. 2016. Pengaruh Orientasi Corporate Social Responsibility (CSR) Terhadap Kinerja Sosial Perusahaan Dengan Kepastian
Lingkungan Sebagai Variabel Pemoderasi.Jurnal Akuntansi Indonesia, 2(1), 37 -50.

Haryono, J., Mahsuni, A. W., dan Junaidi, J. 2018. Implentasi Csr Terhadap Kesejahteraan Hidup Masyarakat. Jurnal Ilmiah Riset Akuntansi, 7(05).

Hidayat, T., Wardati, W., dan Armaini, A. 2013. Pertumbuhan Dan Produksi Sawi (Barssica Juncea L.) Pada Inceptisol Dengan Aplikasi Kompos Tandan Kosong Kelapa Sawit. Thesis. Universitas Riau.

Ikhsan, A. A. N. dan Muharam, H. 2016. Pengaruh Kinerja Lingkungan Terhadap Kinerja Keuangan Studi Pada Perusahaan Yang Terdaftar Di Kementerian Lingkungan Hidup Dan Listing Di Bursa Efek Indonesia (Periode 2008-2014). (Skripsi). Semarang: Fak. Ekonomika Dan Bisnis Universitas Diponegoro (diuplikasikan).

Kementerian Lingkungan Hidup dan Kehutanan .2003.Pendoman Penentuan Status Mutu Air. Terdapat pada

http://www.ditjenppi.menlhk.go.id (diakses pada 01 Juni 2021).

Mapisangka, A. 2009. Implementasi CSR terhadap Kesejahteraan Hidup Masyarakat. Jurnal Ekonomi dan Studi Pembangunan, 1(1).

Mahfuzah, Annisa dan Maimunah. 2019. Implikasi Etika Lingkungan Terhadap Kesejahteraan Ekonomi Masyarakat (Studi Kasus Di Kabupaten Tabalog). At - Taradhi : Jurnal Studi Ekonomi. 10(2), 127 141. 
Naser, R. K. A., dan Bandrang, T. N. 2020. Pengaruh Implementasi Corporate Social Responsibility (CSR) Terhadap Kesejahteraan Masyarakat. Mahatani: Jurnal Agribisnis, 3(1).

Nejati, Mehran dan Ghasemi, S. 2013. Corporate Social Responsibility And Organizational Commitment empirical findings from a developing country. Journal of Global Responsibility, 4 (2), 263-275.

PT.LSI Tbk. 2014.Nurturing Growth Harvesting Succes (Laporan Tahun).

Rahayu, D. P. 2016. Kearifan Lokal Tambang Rakyat Sebagai Wujud Ecoliteracy Di Kabupaten Bangka.Jurnal Hukum Ius Quia Lustum, 23(2), 320 - 342.

Saputra, G., Wirianata, H., dan Rohmiyati, S. M. 2017.Implementasi Indonesian Sustainable Palm Oil (ISPO) Dalam Pelaksanaan CSR Di Perkebunan Kelapa Sawit.Jurnal Agromast, 2 (1).

Siregar, E. Z. $2019 . \quad$ Kontribusi Agroindustri Kelapa Sawit Terhadap Kesejahteraan Masyarakat Melalui Program Corporate Social Responsibility. Jurnal Dakwah dan Pengembangan Masyarakat Desa, 1(2).
Suci, S., Dahlan, Z., dan Yustian, I. 2019. Propil Vegetasi Di Kawasan Hutan Konservasi Suaka Margasatwa Gunung Raya Kecamatan Warkuk Kabupaten Oku Selatan. Jurnal Penelitian Sains, 9 (1), 47 - 53.

Suleman, S., Rajamuddin, U. A., dan Isrun, I. 2016. Penilaian Kualitas Tanah Pada Beberapa Tipe Penggunaan Lahan Di Kecamatan Sigi Biromaru Kabupaten Sigi. E-Jurnal Ilmu Pertanian, 4(6), 712 - 718.

Yakin, S. K. 2017. Analisis mengenai dampak lingkungan (AMDAL) sebagai instrumen pencegahan pencemaran dan perusakan lingkungan. Badamai Law Journal, 2(1), 113-132.

Widayat. 2019. Structural Equation Modeling Partial Least Square. Terdapat pada http://Ikeb.umm.ac.id (di akses pada 12 Juni 2021). 